\title{
Surface temperature estimated with Landsat 8 images and geostatistical tools in the northwestern São Paulo state
}

Antônio H. C. de C. Teixeira, Fernando B. T. Hernandez, Janice F. Leivas, Daniel N. C. Nuñez, Renato F. A. Momesso

Antônio H. C. de C. Teixeira, Fernando B. T. Hernandez, Janice F. Leivas, Daniel N. C. Nuñez, Renato F. A. Momesso, "Surface temperature estimated with Landsat 8 images and geostatistical tools in the northwestern São Paulo state," Proc. SPIE 10421, Remote Sensing for Agriculture, Ecosystems, and Hydrology XIX, 104210F (2 November 2017); doi: 10.1117/12.2277588 


\title{
Surface temperature estimated with Landsat 8 images and geostatistical tools in the northwestern São Paulo state
}

\author{
Antônio H. de C. Teixeira" ${ }^{*}$; Fernando B. T. Hernandez ${ }^{\mathrm{b}}$; Janice F. Leivas ${ }^{\mathrm{a}}$; Daniel N. C. Nuñez \\ Renato F. A. Momesso ${ }^{\mathrm{b}}$

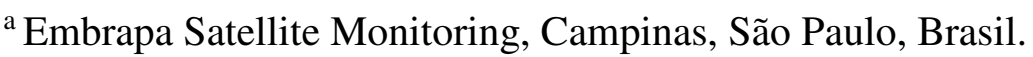 \\ ${ }^{\mathrm{b}}$ São Paulo State University, Ilha Solteira, São Paulo, Brasil
}

\begin{abstract}
In the northwestern side of São Paulo state, irrigated crops are replacing natural vegetation, bringing importance for the development and applications of tools to quantify the energy and water balances. Remote sensing together with geostatistical tools are suitable for these tasks, being the surface temperature $\left(\mathrm{T}_{0}\right)$ one of the radiation balance modelling input parameters. However, due to the importance of high both spatial and temporal resolutions to capture the dynamics of water and vegetation conditions, when the thermal bands are absent in several high-resolution satellites, applications on water resources studies are limited. This paper aimed to test the Moving Average (MA) and the Nearest Point (NP) geostatistical interpolation methods for estimate $\mathrm{T}_{0}$ with and without the Landsat 8 (L8) thermal bands by using a net of agrometeorological stations. In the case of using the L8 satellite thermal radiances, the Plank's low was applied to its bands 10 and 11. Without these bands, $\mathrm{T}_{0}$ was retrieved as residue in the radiation balance. Up scaling the satellite overpass $\mathrm{T}_{0}$ to daily scale resulted in a root mean square error (RMSE) of only 1.72 and $1.74 \mathrm{~K}$ when compared with values resulted from the MA and NP applications with the residual method, respectively. However, the MA method seemed to be more suitable than the NP one, being concluded that the coupled use of high spatial resolution images without a thermal band and interpolated weather data throughout the MA method is suitable for large-scale energy and water balance studies.
\end{abstract}

Keywords: geosciences, radiation balance, interpolation methods.

\section{INTRODUCTION}

The northwestern side of São Paulo state, besides experiencing climate changes, irrigated crops are replacing natural vegetation at the vicinities of the hydrological basins "Turvo/Grande", "São José dos Dourados", and "Baixo Tietê". Considering these land use changes, it is becoming important the development and applications of tools for quantifying the energy and water balances on large scales. Remote sensing together with geostatistical tools for weather data interpolation are suitable for this task, being the surface temperature $\left(\mathrm{T}_{0}\right)$ one of the modelling input parameters ${ }^{1-3}$.

For acquiring the energy and water balance components from satellite images, in general their thermal bands are used for estimating the radiometric $\mathrm{T}_{0}$. However, due to the importance of high both spatial and temporal resolutions to capture the dynamics of water and vegetation conditions, when the thermal bands are absent in several high-resolution satellites, application in water resources studies are limited. Teixeira et al. ${ }^{1}$ developed and tested a methodology with Landsat 5 and RapidEye images, in which $T_{0}$ is acquired as residue in the radiation balance (the residual method), combining remote sensing parameters and agrometeorological stations in the Brazilian Northeast.

Although the residual method works well, opening the opportunities for using satellites with high both spatial and temporal resolutions, without thermal bands, the accuracy of the results will depend on the agrometeorological station densities and on the geostatistical interpolation method used. This paper aimed to test the Moving Average (MA) and the Nearest Point (NP) methods to estimate $\mathrm{T}_{0}$ without the Landsat 8 thermal band by using a net of agrometeorological stations in the northwestern side of the São Paulo state, Brazil. The results for this specific study region encourage the coupled use of

*heriberto.teixeira@embrapa.br; Phone 5519 3211-6200; Fax: 55 19 3211-6222; www.cnpm.embrapa.br

Remote Sensing for Agriculture, Ecosystems, and Hydrology XIX, edited by

Christopher M. U. Neale, Antonino Maltese, Proc. of SPIE Vol. 10421, 104210F

(C) 2017 SPIE $\cdot$ CCC code: $0277-786 X / 17 / \$ 18 \cdot$ doi: 10.1117/12.2277588

Proc. of SPIE Vol. 10421 104210F-1 
high-resolution satellite images without a thermal band together with weather data having confirmed a suitable interpolation geostatistical tool for application on large scale.

\section{MATERIAL AND METHODS}

\subsection{Study area and data set}

Figure 1 presents the locations of the hydrological basins "Turvo/Grande", "São José dos Dourados" and "Baixo Tietê" and the net of eight agrometeorological stations, together with the county limits in the northwestern side of the São Paulo state, Southeast Brazil.

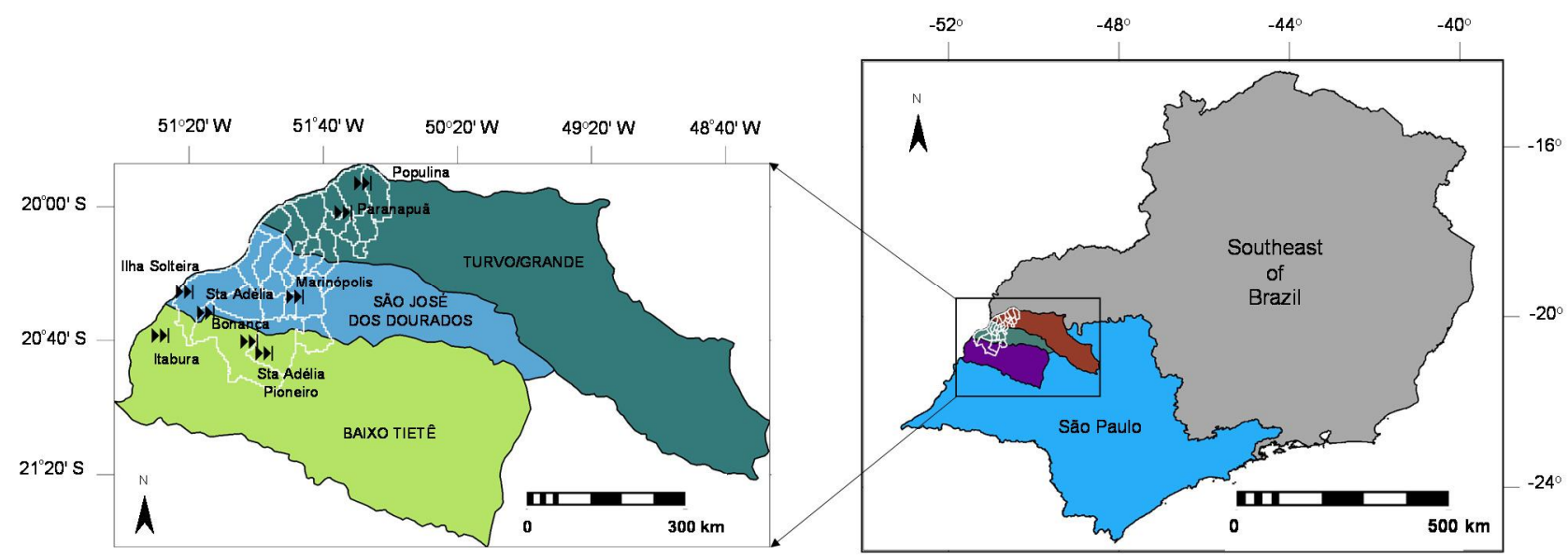

Figure 1. Location of the hydrological basins "Turvo/Grande", "São José dos Dourados" and "Baixo Tietê" together with the county limits in the northwestern side of São Paulo state, Southeast Brazil. Black arrows represent the net of agrometeorological stations.

The study region is located in between the hydrological basins of "Turvo/Grande", "São José dos Dourados" and "Baixo Tietê". The climate presents a dry and mild winter alternated with a wet and hot summer, being the hottest conditions for the whole São Paulo state. Drought events are frequent, limiting the plant developments due to water deficits as long as eight months a year. Vegetation is characterized as forest and savanna, being nowadays replaced by pasture, agriculture and urban areas.

To analyze the different geostatistical interpolation methods for obtaining the $T_{0}$ spatial variation, three Landsat 8 images, involving distinct thermohydrological conditions along the year 2014 were used, together with weather data from a net of eight agrometeorological stations. The satellite images were acquired at the days of the year (DOY) 028 - January 28, 204 - July 23 and 284 - October 11 . The interpolated daily weather data in the modelling process were global solar radiation $\left(\mathrm{R}_{\mathrm{G}}\right)$ and air temperature $\left(\mathrm{T}_{\mathrm{a}}\right)$, with the same spatial resolution of the Landsat visible and infrared bands $(30 \mathrm{~m})$.

The geostatistical interpolation tools tested were the Moving Average (MA) and the Nearest Point (NP) methods, which were compared against the $T_{0}$ estimations resulted from the Plank's low applied to the Landsat 8 thermal bands. In the MA method the output values for a pixel is calculated as the sum of the products of weights and point values, divided by the sum of the weights. Weight values are obtained in such a way that points close to an output pixel obtain large weights while points further away obtain small ones. In the NP method, the value of the nearest point is assigned to the pixels according to the Euclidean distance. This last method offers a quick way to obtain a Thiessen map from point data. 


\subsection{Modeling steps}

Figure 2 presents the flowchart for modelling $\mathrm{T}_{0}$ throughout the coupled use of Landsat 8 remote sensing parameters and interpolated weather data with and without the satellite thermal bands.

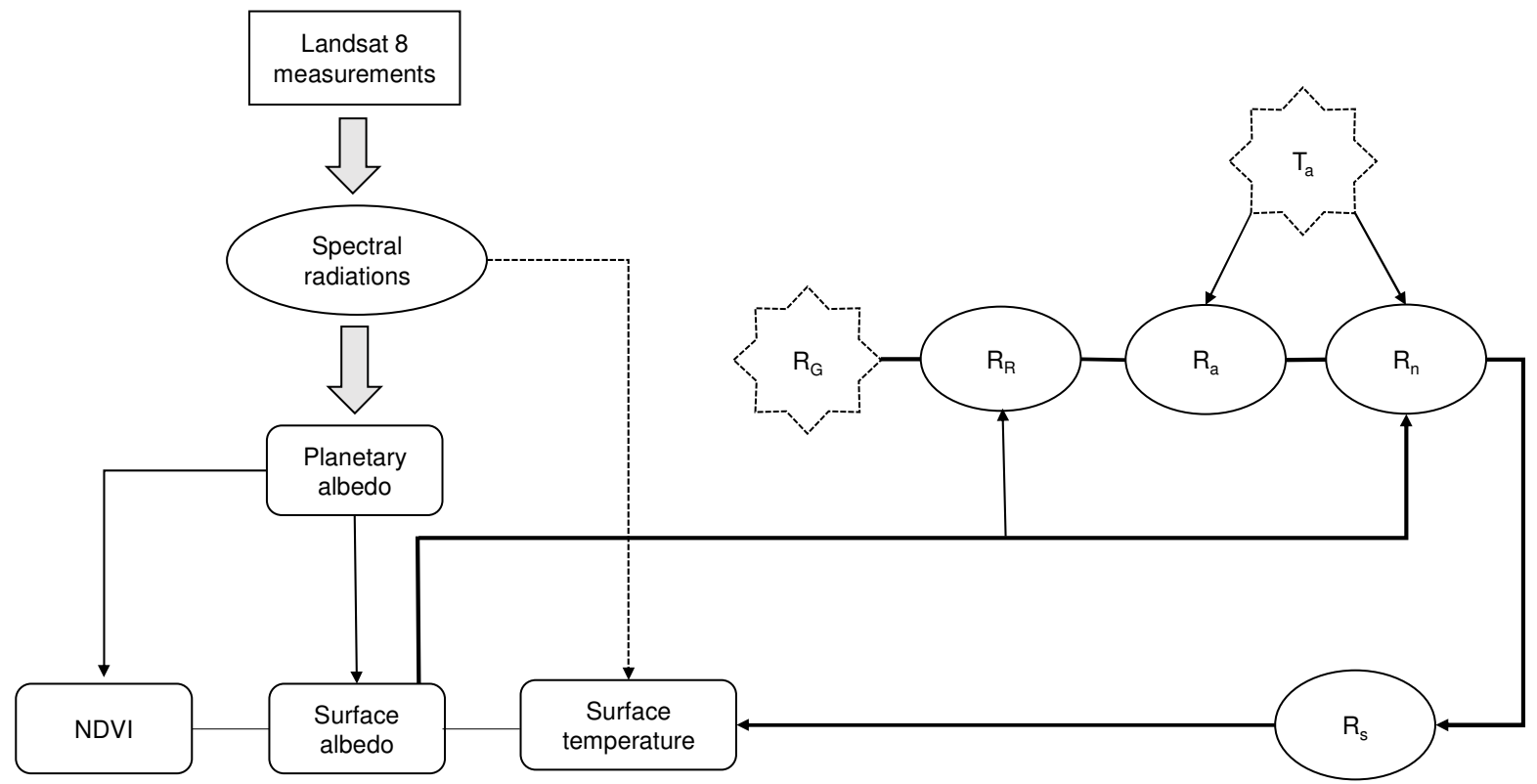

Figure 2. Flowchart for estimating the surface temperature $\left(\mathrm{T}_{0}\right)$ by coupling Landsat 8 remote sensing parameters and interpolated weather data with and without the satellite thermal bands.

From Figure 2, after acquiring the spectral radiations $\left(\mathrm{L}_{b}\right)$ for each band (b) from 1 to 7 , the planetary albedo for each one $\left(\alpha p_{b}\right)$ is calculated as:

$$
\alpha p_{b}=\frac{L_{b} \pi d^{2}}{R_{b} \cos \varphi}
$$

where $\mathrm{d}$ is the relative Earth-Sun distance; $\mathrm{RT}_{\mathrm{b}}$ is the mean solar radiation at the top of the atmosphere for the band and $\varphi$ is the solar Zenith angle.

The planetary albedo taking into account the solar spectrum $\left(\alpha_{\mathrm{p}}\right)$ is estimated as:

$$
\alpha p=\Sigma w_{b} \alpha p_{b}
$$

being $\mathrm{w}_{\mathrm{b}}$ the weight for each band, computed as the ratio of the incident solar radiation in each band wavelength interval (1 to 7) and the incident solar radiation involving the wave-length interval for all the bands ${ }^{3}$.

By using the Landsat 8 thermal region, the spectral radiations from bands $10\left(\mathrm{~L}_{10}\right)$ and $11\left(\mathrm{~L}_{11}\right)$ are converted to brightness temperatures $\left(\mathrm{T}_{\mathrm{br}}\right)$ by inverting the Plank's low in their respective wavelength ranges:

$$
\mathrm{T}_{\mathrm{b}}=\frac{\mathrm{K}_{2}}{\ln \left(\frac{\mathrm{K}_{1}}{\mathrm{~L}_{\mathrm{b}}+1}\right)}
$$


where $K_{1}$ and $K_{2}$ are conversion coefficients for Landsat 8 . The average pixel values from the $T_{10}$ and $T_{11}$ images were considered for $\mathrm{T}_{\mathrm{br}}$.

The results for $\alpha_{\mathrm{p}}$ and $\mathrm{T}_{\mathrm{br}}$ are atmospherically corrected throughout regression equations to retrieve the surface albedo $\left(\alpha_{0}\right)$ and $\mathrm{T}_{0}$, respectively ${ }^{3}$.

The reflected solar radiation $\left(\mathrm{R}_{\mathrm{R}}\right)$ is estimated as:

$$
\mathrm{R}_{\mathrm{R}}=\alpha_{0} \mathrm{R}_{\mathrm{G}}
$$

The long-wave atmospheric radiation $\left(\mathrm{R}_{\mathrm{a}}\right)$ is calculated by applying the Stefan-Boltzmann low:

$$
\mathrm{R}_{\mathrm{a}}=\sigma \varepsilon_{\mathrm{A}} \mathrm{T}_{\mathrm{a}}^{4}
$$

where $\varepsilon_{\mathrm{A}}$ is the atmospheric emissivity; and $\sigma$ is the Stefan-Boltzmann constant $\left(5.67 \times 10^{-8} \mathrm{~W} \mathrm{~m}^{-2} \mathrm{~K}^{-4}\right)$.

The radiation balance parameter $\varepsilon_{\mathrm{A}}$ was calculated as follows ${ }^{1-2}$ :

$$
\varepsilon_{\mathrm{A}}=\mathrm{a}_{\mathrm{A}}(-\ln \tau)^{\mathrm{b}_{\mathrm{A}}}
$$

where $\tau$ is the short-wave atmospheric transmissivity calculated as the ratio of $R_{G}$ to the incident solar radiation at the top of the atmosphere; and $\mathrm{a}_{\mathrm{A}}$ and $\mathrm{b}_{\mathrm{A}}$ are regression coefficients 0.94 and 0.10 , respectively.

The regression coefficients of Eq. 6 in this paper are in between those obtained for Idaho (Allen et al. ${ }^{5} ; a_{A}=0.85$ and $b_{A}=$ 0.09 ) and for Egypt (Bastiaanssen et al. ${ }^{6} ; a_{A}=1.08$ and $b_{A}=0.26$ ).

$\mathrm{R}_{\mathrm{n}}$ can be described by the 24-hour values of net shortwave radiation, with a correction term for net longwave radiation, the Slob equation ${ }^{3}$ :

$$
\mathrm{R}_{\mathrm{n}}=\left(1-\alpha_{0}\right) \mathrm{R}_{\mathrm{G}}-\mathrm{a}_{\mathrm{L}} \tau
$$

where $\mathrm{a}_{\mathrm{L}}$ is the regression coefficient of the relationship between net long wave radiation and $\tau$ on a daily scale.

Because of the thermal influence on longwave radiation via the Stephan Boltzmann equation, a previous study investigated whether the variations of the $a_{L}$ coefficient from Eq. 7 could be explained by variations in 24 hours $T_{a}{ }^{7}$ :

$$
\mathrm{a}_{\mathrm{L}}=\mathrm{aT}-\mathrm{b}
$$

where $\mathrm{a}$ and $\mathrm{b}$ are regression coefficients found to be 6.99 and 39.93 respectively. A constant value of $\mathrm{a}_{\mathrm{L}}=110$ was previously applied by Bastiaanssen et al. ${ }^{6}$ without considering the thermal spatial differences.

Having estimated $R_{R}, R_{a}$ and $R_{n}$, the emitted surface longwave radiation $\left(R_{s}\right)$ was acquired as residue in the radiation balance equation:

$$
R_{S}=R_{G}-R_{R}-R_{a}-R_{n}
$$

Then, the surface temperature $\left(\mathrm{T}_{0}\right)$ was estimated as ${ }^{1,2}$ :

$$
\mathrm{T}_{0}=\sqrt[4]{\frac{\mathrm{R}_{\mathrm{S}}}{\sigma \varepsilon_{\mathrm{S}}}}
$$


where the surface emissivity $\left(\varepsilon_{\mathrm{S}}\right)$ was obtained as follows ${ }^{3}$ :

$$
\varepsilon_{\mathrm{S}}=\mathrm{a}_{\mathrm{S}}(\ln \mathrm{NDVI})+\mathrm{b}_{\mathrm{S}}
$$

and $a_{S}$ and $b_{\mathrm{S}}$ are regression coefficients 0.06 and 1.00 , respectively.

The original coefficients ${ }^{6}$ of Eq. 11 are as $=0.047$ and $b_{s}=1.009$, being slightly different from those for Brazil.

Even with small differences on both $\varepsilon_{\mathrm{A}}$ and $\varepsilon_{\mathrm{S}}$, when comparing the Brazilian values with those from other environments, estimate errors from these emissivities in the São Paulo state should be self-cancelled on the accounting of the upward and downward radiation balance components.

\section{RESULTS AND DISCUSSION}

\subsection{Weather conditions}

The weather data that most drives the water and vegetation conditions, and them the thermal ranges, are $\mathrm{R}_{\mathrm{G}}$, pluvial precipitation $(\mathrm{P})$ and the reference evapotranspiration $\left(\mathrm{ET}_{0}\right)$. These data are presented in Figure 3 on a decade time scale in terms of day of the year (DOY), inside the period of the Landsat image acquisitions from January to October 2014 with data from the agrometeorological station "Ilha Solteira" (see also Figure 1).

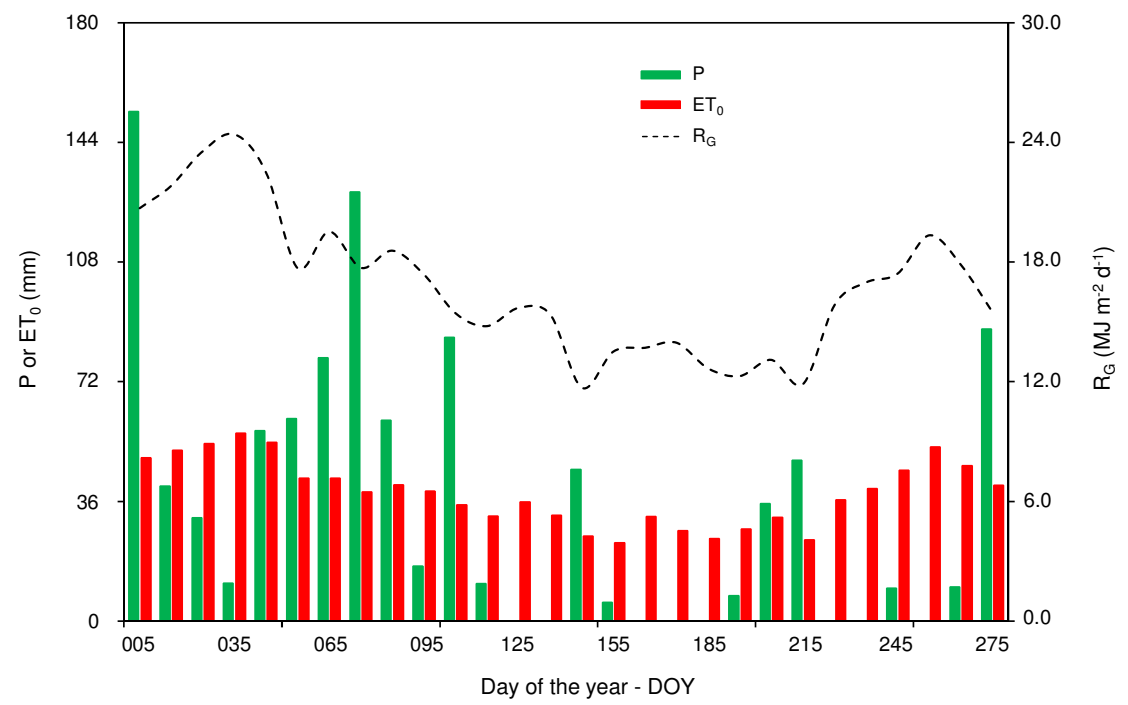

Figure 3. Decade values for the weather variables inside the Landsat image acquisition periods from January to October 2014. Data from the "Ilha Solteira" agrometeorological station are pluvial precipitation $(\mathrm{P})$, global solar radiation $\left(\mathrm{R}_{\mathrm{G}}\right)$ and reference evapotranspiration $\left(\mathrm{ET}_{0}\right)$.

From the three weather parameters showed in Figure 3, P was the most variable along the image acquisition period, with higher values at the start of January to the first half of March (DOY 005 and 075), when the decade values were above 110 $\mathrm{mm}$. Some dry conditions with rainfall absence happened in May (DOY 115 to 145), from June to July (DOY 155 to 185), in August (DOY 215 to 235) and in September (DOY 245 to 255).

Although with lower amplitudes than $\mathrm{P}$, the highest $\mathrm{ET}_{0}$ values happened during the rainy season, favoring the vegetation development and water fluxes. The lowest atmospheric demands, with decade $\mathrm{ET}_{0}$ values bellow $30 \mathrm{~mm}$, were from the end of May (DOY 135) to the end of July (DOY 215), period with low P or without rains. 
The $\mathrm{R}_{\mathrm{G}}$ tendency along the year followed that for $\mathrm{ET}_{0}$, being the highest levels, above $20 \mathrm{MJ} \mathrm{m}^{-2} \mathrm{~d}^{-1}$, from the start of the year to the first half of February (DOY 045). The image of January 28, processed under these last conditions, besides involving high evapotranspiration rates, the remote sensing parameters will also reflect increasing photosynthetic activity. $\mathrm{R}_{\mathrm{G}}$ together with air temperature $\left(\mathrm{T}_{\mathrm{a}}\right)$ are important in the radiation and energy balance, thus, affecting $\mathrm{T}_{0}$ estimations by using the residual method.

\subsection{Geostatistical tools}

Figure 4 shows the $R_{G}$ spatial and temporal distributions for the Landsat 8 images acquisition days resulted from the application of the Moving Average (MA) and Nearest Point (NP) geostatistical interpolation methods, in the counties involved by the net of agrometeorological stations in the northwestern side of São Paulo state, Southeast Brazil.
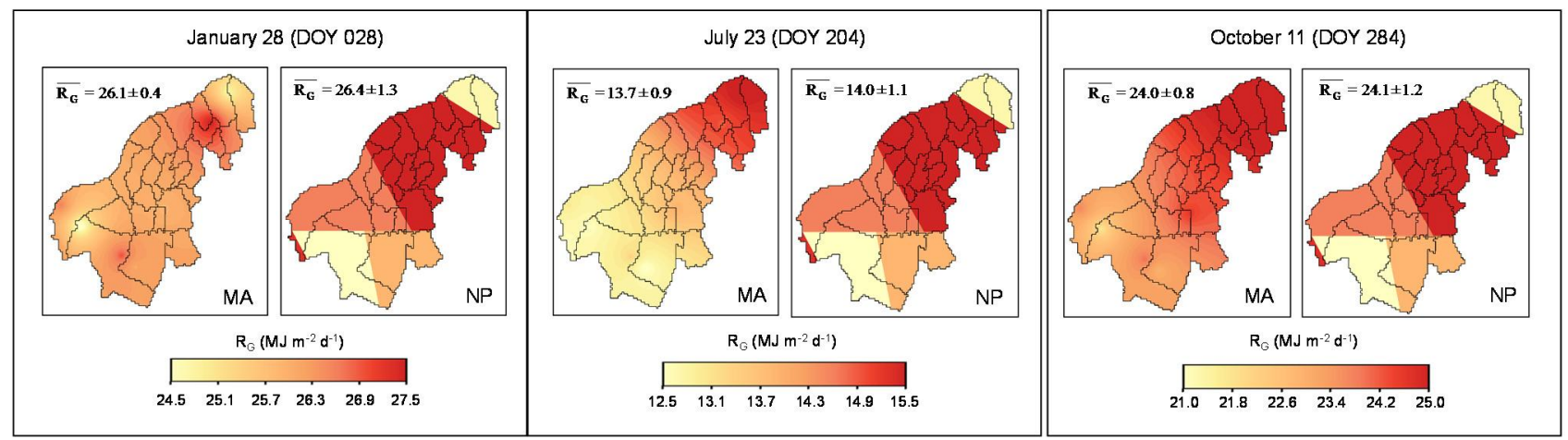

Figure 4. Spatial and temporal distributions of the global solar radiation $\left(\mathrm{R}_{\mathrm{G}}\right)$ for the Landsat 8 images acquisition days resulted from the applications of the Moving Average (MA) and Nearest Point (NP) geostatistical interpolation methods, in the counties involved by the net of agrometeorological station in the northwestern side of the São Paulo state, Southeast Brazil. The over bars means averages, showed together with the standard deviations.

Accurately quantifying the $\mathrm{R}_{\mathrm{G}}$ spatially and temporally is important, as this weather parameter represents the sum of the direct and diffuse radiations, integrated in all short-wave lengths, reaching the vegetated surfaces, strongly acting on both evapotranspiration and biomass production. Although these variations are detected by both geostatistical interpolation methods, in average terms there were no significant differences between them, independently of the thermohydrological conditions along the year, with the highest $\mathrm{R}_{\mathrm{G}}$ levels happening in January.

However, higher homogeneity resulted from the MA method application is noticed, evidenced by the lower standard deviations, in relation to the NP one, which retrieved five distinctions regions with abrupt changes in the pixel values that will affect the radiation balance components, and then, the $\mathrm{T}_{0}$ values retrieved by residue in this balance. Considering the maximum and minimum pixel values, the lowest differences between the geostatistical interpolation methods happened in the middle of the year, winter solstice time in the South hemisphere.

Figure 5 shows the $T_{a}$ spatial and temporal distributions for the Landsat 8 images acquisition days resulted from the application of the Moving Average (MA) and Nearest Point (NP) geostatistical interpolation methods, in the counties involved by the net of agrometeorological stations in the northwestern side of São Paulo state, Southeast Brazil. 

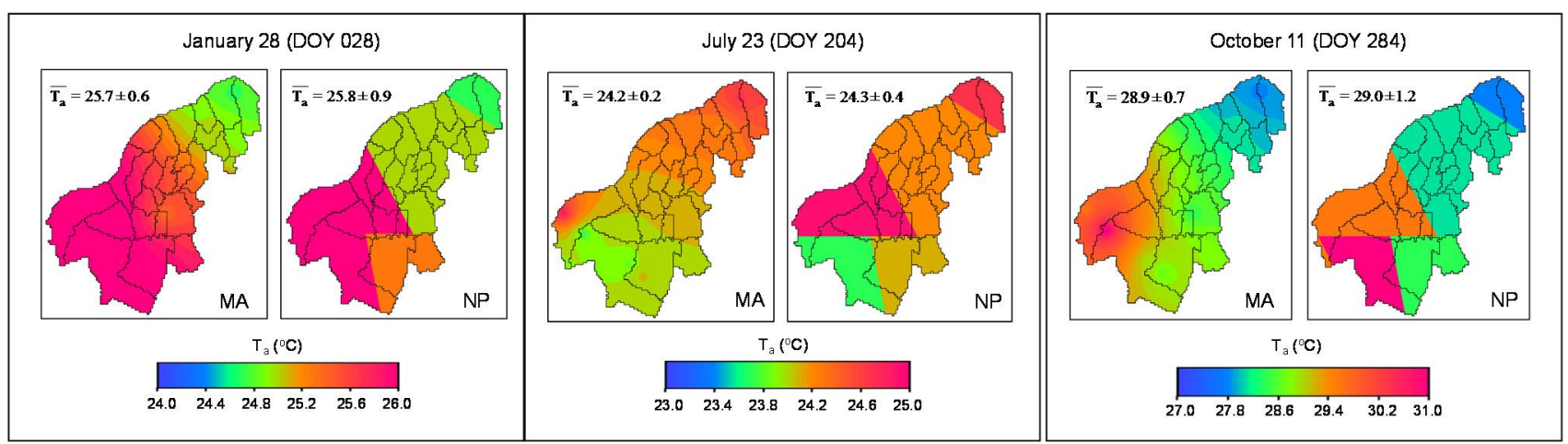

Figure 5. Spatial and temporal distributions of the surface temperatures $\left(\mathrm{T}_{\mathrm{a}}\right)$ for the Landsat 8 images acquisition days resulted from the applications of the Moving Average (MA) and Nearest Point (NP) geostatistical interpolation methods, in the counties involved by the net of agrometeorological station in the northwestern side of São Paulo state, Southeast Brazil. The over bars means averages, showed together with the standard deviations.

The lower atmosphere absorbs long-wave radiation from the surface and warm, sending it back with intensity depending on $T_{a}$, thus, it is related to $T_{0}$, which in turn will depend on the net long-wave radiation balance. From Figure 5, the spatial and temporal $T_{a}$ variations along the year are evident, however, differently from the $R_{G}$ annual dynamics, but even with also the lowest values happening in the middle of the year (DOY 204), the highest thermal conditions were in October (DOY 284).

In average, similarly to $R_{G}$, there were no significant differences between the geostatistical interpolation methods along the year, with larger spatial homogeneity for the MA method application, highlighted by the lower standard deviations, when comparing to the NP one. It is also noticed five distinct pixel divisions when applying the NP method, what will affect the spatial distribution of the radiation balance components, and then $\mathrm{T}_{0}$ retrieved as residue in this balance.

\subsection{Surface temperature retrieving}

The $\mathrm{T}_{0}$ acquirement through the Landsat 8 thermal bands is done at the satellite overpass time. To up scale the remote sensing instantaneous to daily values for comparing with those ones estimated by the residual method, applying the MA and NP geostatistical methods, firstly regressions between the air and surface temperature at the satellite overpass time were performed ( $\mathrm{T}_{0_{-} \text {sat }}$ and $\mathrm{T}_{\mathrm{a}_{-} \text {sat }}$, respectively). Applying the resulted regression equation to the daily values of air temperature the corresponding ones for surface temperature $\left(T_{0 \_24}\right)$ were estimated, which in turn were correlated with $\mathrm{T}_{0_{-} \text {sat. }}$. Figure 6 shows the regressions between instantaneous and daily temperature values.
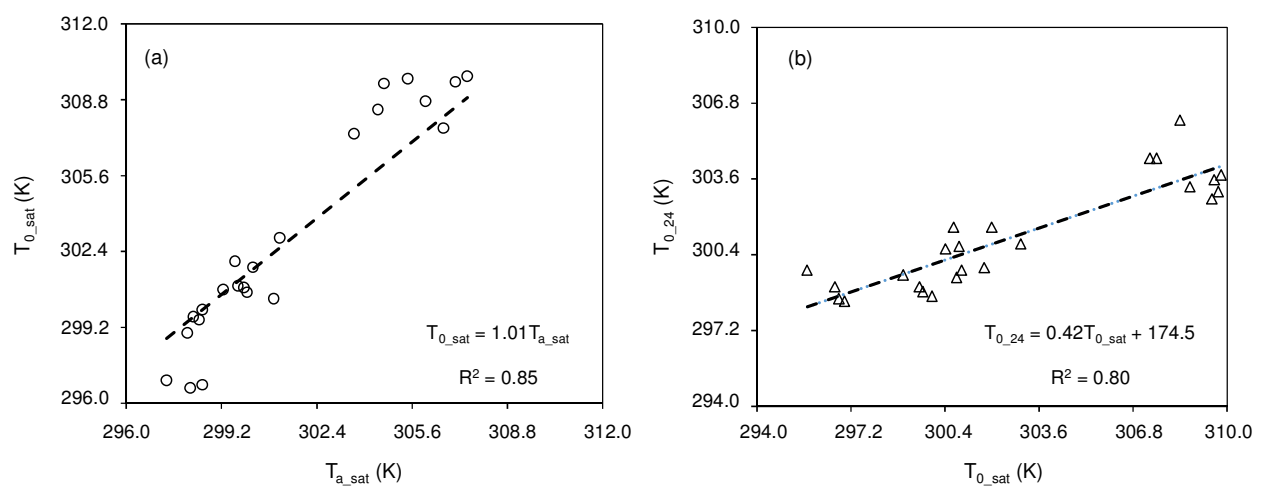

Figure 6. Regression equations between the satellite overpass and daily values. (a) surface and air temperature at the satellite overpass time $\left(\mathrm{T}_{0 \_ \text {sat }}\right.$ and $\mathrm{T}_{\mathrm{a}_{\_} \text {sat }}$, respectively); and (b) estimated daily values and instantaneous satellite overpass surface temperature $\left(\mathrm{T}_{0 \_24}\right.$ and $\mathrm{T}_{0 \_}$sat, respectively). 
The equation presented in Figure $6 \mathrm{~b}$ was applied to the $\mathrm{T}_{0_{-} \text {sat }}$ image for comparisons. Figure 7 represents the spatial distributions for the estimated daily values of surface temperatures $\left(\mathrm{T}_{0 \_24}\right)$ resulted from the Plank's low to the Landsat 8 thermal bands (T) and from the MA and NP geostatistical tools applied with the residual method in the northwestern São Paulo state, Southeast Brazil.
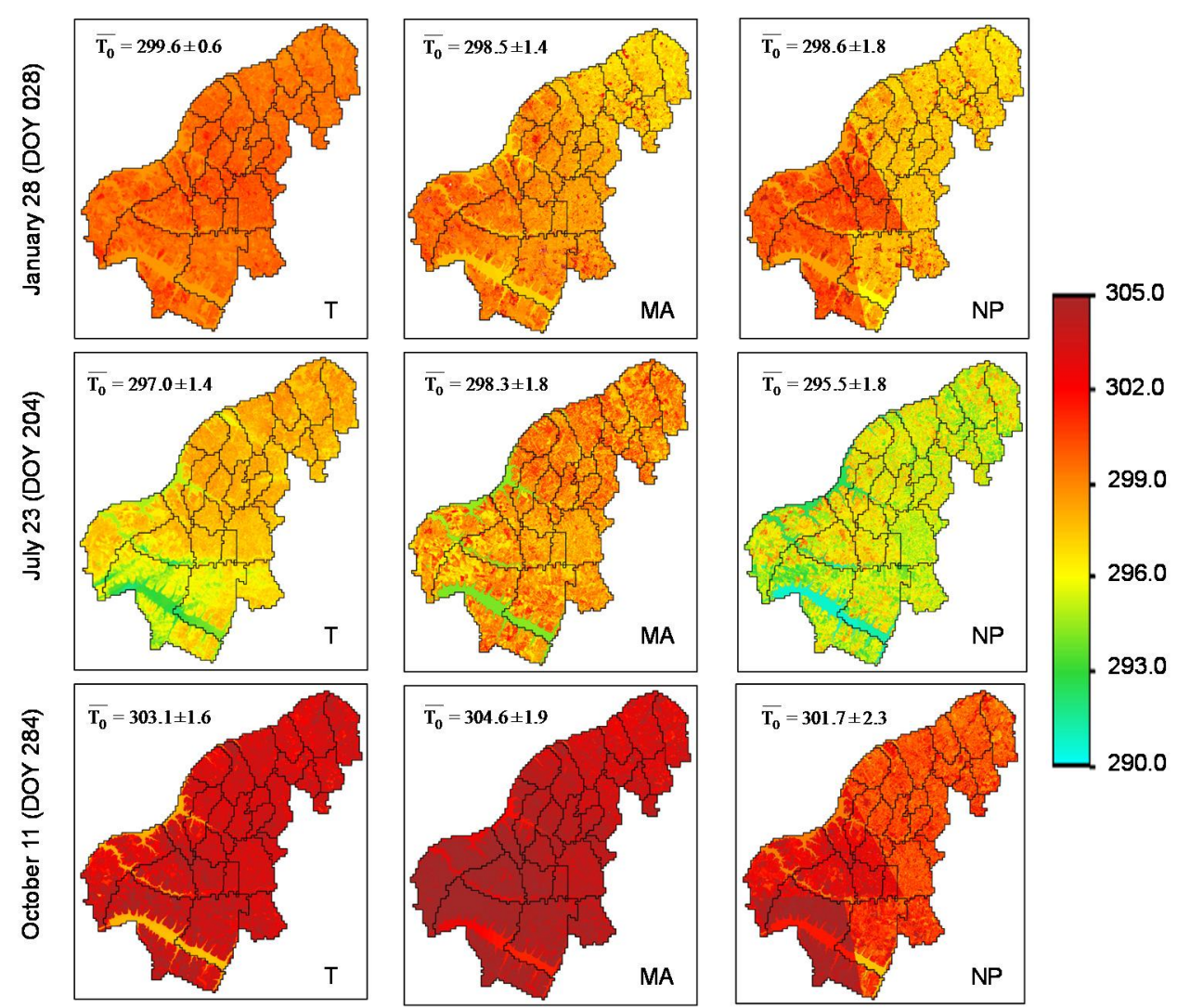

Figure 7. Spatial and temporal distribution for the daily the surface temperature $\left(\mathrm{T}_{0 \_} 24\right)$ values up scaled results from the Plank's low to the Landsat 8 thermal bands (T) and from the MA and NP geostatistical tools applied to the residual method in the northwestern São Paulo state, Southeast Brazil.

Both the spatial and temporal $\mathrm{T}_{0}$ variations affect the available energy to the mixed agro-ecosystems along the year, through their interference in the large-scale long-wave radiation balance. The lowest $\mathrm{T}_{0}$ values happened under irrigation conditions and for water bodies, when compared with those from the naturally drier areas. These effects were more evident under the climatically driest and coldest conditions in the middle of the year (image of DOY 204), clearly evidencing the rivers and irrigated crops (see also Figure 3).

The 24-hour estimated $\mathrm{T}_{0}$ values were not significantly different from those at the satellite overpass time, being the $\mathrm{T}_{0 \_24}$ averages, 99.4, 98.2 e $101.0 \%$ from the corresponding ones for $\mathrm{T}_{0 \_ \text {sat }}$, involving the different conditions along the year represented by the images for January (DOY 028), July (DOY 204) and October (DOY 284).

Franco et al. ${ }^{8}$ analyzing $\mathrm{T}_{0 \_ \text {sat }}$, retrieved from 14 Landsat 8 images under different environmental conditions and agroecosystems in the "Baixo Tietê" hydrological basin (see Figure 1), found average values ranging from 292.0 to $308.6 \mathrm{~K}$, slightly higher than those in the current study $(291.7$ a $306.2 \mathrm{~K}$ ). The authors reported values between 297.0 and $299.0 \mathrm{~K}$ for water bodies; from 289.0 to $295.0 \mathrm{~K}$ for irrigated crops; and of $313.0 \mathrm{~K}$ for bare soil, inside the range depicted in Figure 7 when considering the three different conditions along the year and methods for acquiring $\mathrm{T}_{0}$. 
Independently of the method used, $\mathrm{T}_{0}$ spatial and temporal variations in the natural ecosystems can be mainly attributed to different both $\mathrm{R}_{\mathrm{G}}$ and moisture levels. However, for irrigated crops, as water is in general regularly applied, these variations are also related to crop stages and cultural managements.

Among all analyzed methods, in general the highest $T_{0}$ values coincided with the largest $R_{G}$ levels, conditions represented by the image of DOY 028. Small differences arisen between the geostatistical methods (MA and NP) and when comparing their results with those from the Plank's low application on the Landsat 8 thermal bands (T). However, higher spatial homogeneity is clear for the MA application. Taking into account the T results as a reference and the pixel averages involving all conditions along the year, the root mean square error (RMSE) resulted only 1.72 and $1.74 \mathrm{~K}$ for the MA and NP methods.

Considering little differences between the $\mathrm{T}_{0}$ acquirements with and without the thermal band, it was concluded that the MA geostatistical method has a good performance to interpolate the modelling input weather data to be used together with the residual method. This give strong confidence for using high-resolution satellite images applying these techniques with absence of a thermal band in energy and water balance studies on large scales, having the availability of spatially distributed weather data.

\section{CONCLUSIONS}

Landsat 8 images were used together with weather data, with and without their thermal bands, respectively applying the Pank's low and by using the moving average (MA) and nearest point (NP) geostatistical interpolation methods, for acquiring the surface temperature, in the northwestern side of São Paulo state, Brazil. It was concluded that MA method seems to be more suitable than the NP one, when comparing them with the use of the satellite spectral thermal bands. With these tests, one can have trust for using high-resolution satellite images without a thermal band, having available spatially distributed weather data.

\section{ACKNOWLEDGEMENTS}

To CNPq, for the financial support to projects dealing with large-scale energy and water balance determinations.

\section{REFERENCES}

[1] Teixeira, A.H. de C., Leivas, J.F. and Silva, G.B., "Options for using Landsat and RapidEye satellite images aiming the water productivity assessments in mixed agro-ecosystems," Proc. SPIE, 9998, 99980A-1-99980A-11 (2016a).

[2] Teixeira, A.H. de C., Leivas, J.F., Ronquim, C.C. and Victoria, D. de C. "Sugarcane water productivity assessments in the São Paulo state, Brazil," Int. J. Remote Sens. App., 6, 84-95 (2016b).

[3] Teixeira, A.H. de C., Leivas, J.F., Hernandez, F.B.T. and Franco, R.A.M. "Large-scale radiation and energy balances with Landsat 8 images and agrometeorological data in the Brazilian semiarid region," J. App. Remote Sens., 11(1), 01630 (2017).

[4] Santos. G.O., Hernandez. F.B.T. and Rossetti. J.C. "Balanço hídrico como ferramenta ao planejamento agropecuário para a região de Marinópolis, noroeste do Estado de São Paulo," Rev. Bras. Agric. Irrigada, 4, 142-149 (2010).

[5] Allen, R.G., Hartogensis, O. and de Bruin, H.A.R., "Long-wave radiation over alfafa during the RAPID field campaign in southern Idaho," Research Report, Kimberly, Univ. of Idaho, Id (2000).

[6] Bastiaansssen, W.G.M., Menenti, M., Feddes, R.A., Roerink, G.J. and Holtslag, A.A.M., "A remote sensing surface energy balance algorithm for land (SEBAL) 1. Formulation," J. Hydrol., 212-213, 198-212 (1998).

[7] Teixeira, A.H. de C., Bastiaanssen, W.G.M., Ahmad, M-ud-D, Bos, M.G. and Moura, M.S.B., "Analysis of energy fluxes and vegetation-atmosphere parameters in irrigated and natural ecosystems of semi-arid Brazil," J. Hydrol., 362, 110-127 (2008).

[8] Franco, R.A.M.; Hernandez, F.B.T.; Teixeira, A.H. de C.; LEIVAS, J.F.; NUNEZ, D.N.C.; Neale, C.M.U., "Water productivity mapping using Landsat 8 satellite together with weather stations," Proc. SPIE, 9998. 99981H-1-99981H12 (2016). 